\title{
LOS INICIOS DE LA LUCHA FEMINISTA CONTRA LA PROSTITUCIÓN: POLÍTICAS DE REDEFINICIÓN Y POLÍTICAS ACTIVISTAS EN EL SUFRAGISMO INGLÉS ${ }^{1}$
}

\author{
Ana de Miguel Álvarez \\ Eva Palomo Cermeño \\ Universidad Rey Juan Carlos
}

\begin{abstract}
RESUMEN: Este artículo analiza los inicios del proceso de deslegitimación del conjunto de ideas y creencias que presentan la prostitución como una realidad normal, natural o, en todo caso, como "un mal menor". Se analiza este proceso en el contexto del sufragismo inglés. Por un lado se reconstruye la genealogía de las ideas críticas que pusieron las bases para deslegitimar la visión tradicional de la prostitución y para comenzar a construir un nuevo marco feminista de interpretación. Por otro lado se analiza el surgimiento y desarrollo del movimiento abolicionista y algunas de sus estrategias y conquistas fundamentales: subir la edad del consentimiento a los 16 años y poner fin a los intentos parlamentarios de reglamentar un mercado de prostitución femenina.

Palabras clave: Prostitución, abolicionismo, sufragismo, Josephine Butler, John Stuart Mill.

\section{BEGINNINGS OF THE FEMINIST STRUGGLE AGAINST PROSTITUTION: POLITICS OF REDEFINITION AND ACTIVISM WITHIN BRITISH SUFFRAGISM}

ABSTRACT: This paper analyzes the beginnings of the process to delegitimize the set of ideas and beliefs that present prostitution as a normal and natural reality or as the lesser evil, within the context of the British Woman's

1. Este trabajo se ha realizado en el contexto del Proyecto de Investigación "Debates teóricos sobre la prostitución: un análisis de los fundamentos filosóficos, históricos y legales", referencia URJC-CM-2010-CSH-5101 y subvencionado por la URJC y la CAM. 
Suffrage movement. On one hand, the genealogy of critical ideas involved in establishing the basis to delegitimize the traditional view of prostitution and the building of a new feminist framework of interpretation, is reconstructed. On the other hand, the emergence and development of the abolitionist movement and some of its main strategies and achievements are analyzed: rising the age of consent up to 16 and ending the parliamentary attempts to regulate a market of female prostitution.

Keywords: Prostitution, abolitionism, woman's suffrage, Josephine Butler, John Stuart Mill.

\section{Políticas de redefinición y políticas reivindicativas en los movimientos sociales}

Una de las consecuencias del proceso de globalización en que estamos inmersos es el aumento y expansión de un mercado internacional de prostitución de mujeres. Contra todo pronóstico, este aumento afecta también a los países comprometidos con el principio de la igualdad entre hombres y mujeres. Ante esta situación -muy similar en algunos aspectos a la que tuvo lugar en los inicios del capitalismo y el industrialismo, y que llevó a los burdeles y las calles a una cantidad insoportable de niñas y mujeres- han surgido dos posiciones teóricas y políticas que están protagonizando un duro enfrentamiento. Estas posiciones son la abolicionista y la reglamentarista. Las definimos brevemente. Las posturas que defienden la legalización se expresan en un arco que va desde la llamada "teoría del mal menor", muy popular a lo largo de la historia, hasta los nuevos planteamientos que defienden que la prostitución es un trabajo de servicios semejante a cualquier otro. Su nervio teórico estriba en defender que los hombres tienen derecho a disponer de servicios sexuales $y$, si hay mujeres dispuestas a suministrárselos hay que aceptar y legalizar esa situación contractual que consideran de consentimiento. Por su lado, el abolicionismo hace un análisis muy crítico de las relaciones "de consentimiento" cuando, en realidad, median grandes desigualdades económicas y de género entre los y las que consienten. Se considera, además, que la prostitución, con su modelo de servidumbre a la voluntad y los deseos masculinos, es un factor importante en la reproducción de la desigualdad entre los sexos, y mantienen como horizonte regulador moral la desaparición de la prostitución, al igual que en su día desapareció la esclavitud de los negros².

Este enfrentamiento es lo que ha motivado que hayamos iniciado una investigación sobre la concepción de la prostitución en la genealogía del feminismo. Estamos convencidas de que la mirada hacia la historia y la reconstrucción de las posiciones feministas pueden contribuir a clarificar los debates actuales.

2. Existe una amplia bibliografía al respecto. Pueden consultarse las obras de Gail Peterson y Raquel Osborne para la perspectiva regulacionista y las de Sheila Jeffreys y Carole Pateman para la abolicionista. 
Este trabajo se centra en la reconstrucción de un momento especialmente importante, la lucha por la ciudadanía a lo largo del siglo diecinueve. De este momento nos interesan tanto sus prácticas reivindicativas como sus prácticas teóricas. Y es que los enfoques constructivistas sobre los movimientos sociales nos han confirmado la importancia de mantener la distinción conceptual entre estos dos tipos de prácticas o políticas del feminismo, las políticas reivindicativas y las políticas de redefinición o elaboración de marcos teóricos de reinterpretación de la realidad ${ }^{3}$.

Los enfoques constructivistas han recuperado el concepto de marco, definido en su día por Goffman como el conjunto de las orientaciones mentales que permiten organizar la percepción y la interpretación ${ }^{4}$. La importancia de los movimientos como creadores de nuevos marcos de interpretación o referencia -"marcos de injusticia"- que pugnan con otros agentes sociales por hacer hegemónica su definición de la situación, no ha dejado de enriquecer el panorama teórico. Nos interesa subrayar que las reivindicaciones objetivas y políticas de los movimientos no se consideran ya como "algo dado", obvio y evidente en sí mismo. Al contrario, se considera que el proceso por el que un colectivo social Ilega a definir como injusto y objeto de cambio social una situación generalmente legitimada por la tradición cultural y la costumbre, es una de las contribuciones más importantes de los movimientos al cambio social. Recordemos que incluso una reivindicación tan aparentemente "natural o evidente" hoy como el derecho al voto femenino era rechazado como antinatural por la mayor parte de la sociedad, mujeres incluidas.

Desde esta perspectiva, y sin infravalorar la presencia combativa de los movimientos en la esfera pública, obtenemos una imagen de las redes de los movimientos y de su acción interna y externa cercana a los laboratorios de innovación cultural de los que hablara Melucci ${ }^{5}$. En estos laboratorios, los nudos de las redes feministas, fermenta lentamente la creación de nuevos marcos de referencia, de nuevos significados para interpretar los a menudo demasiado viejos hechos, como la prostitución de mujeres y la violencia patriarcal. Como ha escrito Gusfield, la sola existencia de un movimiento es ya un principio para situar acontecimientos en un marco; presenta un aspecto de la vida social que ya está sometido a discusión pública, aunque anteriormente se hubiera aceptado como la norma: "donde la elección y la disputa estaban ausentes,

3. Hemos desarrollado esta distinción en diversas ocasiones, entre otras en De Miguel, Ana, "Hacia un nuevo Contrato Social: políticas de redefinición y políticas reivindicativas en la lucha feminista" en J.M. Robles El reo de la participación, Madrid, Mínimo Tránsito, 2002; para una aplicación de estos conceptos al tema de la violencia contra las mujeres véase Ana de Miguel, "La violencia de género: la construcción de un marco de interpretación feminista", en Cuadernos de Trabajo Social, no 35 (2005).

4. Cfr. Goffman, Ervin, Frame Analysis, Boston, Northeastern University Press, 1974.

5. Melucci, Alberto "¿Qué hay de nuevo en los nuevos movimientos sociales?, en E. Laraña y J. Gusfield (eds.), Los Nuevos Movimientos Sociales, Madrid, CIS, 1994. 
están ahora presentes las alternativas ${ }^{6}$. En palabras de la teórica feminista Celia Amorós: "conceptualizar es politizar"7. Esta visión que enfatiza la relevancia de la teoría o praxis cognitiva y el protagonismo de los movimientos en los cambios de mentalidad y culturales, es la que vamos a utilizar para explicar y para valorar los profundos cambios que el feminismo está introduciendo en la visión social de la prostitución y el tráfico de mujeres.

Hoy sabemos que uno de los grandes desafíos teóricos del feminismo del siglo diecinueve fue el de desarticular la ideología de la naturaleza diferente y complementaria de los $\operatorname{sexos}^{8}$. La tarea no era fácil, ni mucho menos. Significaba enfrentarse a la autoridad de algunos de los más grandes filósofos de la Ilustración, y a lo que se percibía como un hecho de sentido común indiscutible: las grandes diferencias entre las capacidades y aspiraciones de varones y mujeres. Significaba, también, dar cuenta de por qué tantas mujeres aceptaban la tesis de su inferioridad y asentían a su destino sexual como si fuera fruto de su inclinación personal. Es decir, había que someter a crítica racional y desarticular un sistema de pensamiento, creencias y actitudes que se solapaba con la única realidad posible: un orden eterno y universal en el sentido más fuerte de la palabra. Los argumentos teóricos del movimiento feminista tenían que aportar buenas razones para mostrar que existía un sistema de dominación donde lo que se percibía era consentimiento, para mostrar los beneficios que podían esperarse de cambiar una concepción del orden social que venía estando legitimada por la divinidad, la tradición y, salvo excepciones, la mismísima filosofía moderna. De hecho, la lucha de las sufragistas fue, en buena medida, la lucha por desactivar los ancestrales prejuicios que pesaban sobre la condición femenina y conseguir redefinirla como una condición humana .

En este artículo nos proponemos mostrar que esta misma labor de cuestionamiento crítico de la ideología patriarcal comenzó a desarrollarse también en torno a lo que podemos denominar la ideología o la idea de la prostitución ${ }^{10}$. La ideología según la cual la prostitución de mujeres, con el fin de que los varones accedan libremente a sus cuerpos para su placer sexual, es algo inevitable, normal y natural, inscrito en el orden universal y eterno de los tiempos. La idea de que es el oficio más viejo del mundo. Además hay que subrayar que esta ideología choca frontalmente con el espíritu de la filosofía y la política

6. Gusfield, John, "La reflexividad de los movimientos sociales" en E. Laraña y J. Gusfield (eds.) Los nuevos movimientos sociales.

7. Celia Amorós ha desarrollado esta idea en muchos de sus escritos.

8. La obra de John Stuart Mill The subjection of Women, publicada en 1869 recoge de forma sistemática los argumentos sufragistas para mostrar que las "naturalezas sexuales" son producto de la socialización y el poder coercitivo de las estructuras sociales. Cfr. Mill, J. S. El sometimiento de las mujeres, Madrid, Edaf, 2005.

9. Cfr. Miyares, Alicia, "El sufragismo", en C. Amorós y A. de Miguel, Teoría Feminista. De la llustración a la globalización, vol. 1, Madrid, Minerva, 2005.

10. Cfr. Jeffreys, Sheila, The idea of prostitution, North Melbourne, Spiniflex Press, 1997. 
modernas: justo en el momento en que la filosofía de la época decreta desde la Ilustración y desde el marxismo que no hay nada natural, normal e inevitable en el orden social, la condición femenina y la prostitución de mujeres se teorizan a menudo como un fenómeno ahistórico, atemporal, inmutable. Frente a esta visión hegemónica, teóricos y activistas de ambos sexos comenzaron a desafiar la ideología patriarcal desde una nueva idea, la idea de la igualdad entre hombres y mujeres. Y a mostrar cómo la prostitución constituye un modelo de relación de explotación y opresión en las relaciones entre hombres y mujeres. Además de un factor determinante en la reproducción de la ideología patriarcal más rancia e indulgente con la "debilidad masculina".

\section{El sufragismo y la crítica a la doble moral sexual}

La visión que nos había llegado del sufragismo hasta la revisión que se inició a partir de la segunda ola de feminismo se caracterizaba por considerarlo un movimiento estrictamente político dirigido a la concesión del derecho al voto y por etiquetarlo como "un movimiento burgués". Sin embargo, desde hace ya tiempo los nuevos estudios no hacen sino descubrir y poner de relieve la hondura y lucidez de sus múltiples dimensiones. Si bien es cierto que el medio, y los métodos utilizados, fueron 'políticos', en el sentido tradicional -hoy sabemos que todo lo personal es también político-, pensamos que supuso además transformaciones mucho más profundas en las vidas de las mujeres. Las propuestas del sufragismo cuestionaron el orden social, económico, cultural, psicológico y moral de la época. A lo largo de su desarrollo se produjo una importante redefinición de la moral sexual existente.

Las sufragistas se enfrentaron al peso de la ideología patriarcal del diecinueve, que defendía la existencia de dos esferas separadas, pública y privada ${ }^{11}$, y que objetualizaba a la mujer como 'el sexo'. Se proponían alterar esa percepción esencialista que las catalogaba en función de su biología, negándoles una identidad como seres humanos completos. No olvidemos que las críticas, el rechazo y la violencia que sus detractores dirigieron hacia ellas tenían un fuerte contenido sexual, como lo revelan los insultos recibidos en la calle, los 'diagnósticos' médicos y psicológicos o los escritos de la prensa. El movimiento de mujeres cuestionó, en un contexto adverso, la desigualdad de las mujeres, enfrentándose a la influencia de las instituciones que la perpetuaban: el matrimonio, la ciencia, la cultura, la religión y la ley.

El movimiento sufragista británico fue muy heterogéneo en cuanto a la ideología y a la procedencia social de sus activistas y simpatizantes, y respecto a

11. Sobre el cuestionamiento que hacen las sufragistas de las esferas pública y privada, ver el artículo de Eva Palomo, "Conceptualización de lo público: del sufragismo a nuestros días", en Actas del II Congreso Internacional Koré 'Las mujeres en la esfera pública. De lo privado a lo público: herencias contemporáneas', Universidad Carlos III, Madrid, 2010 (en prensa). 
las diversas formas de entender la estrategia y las tácticas políticas a utilizar. ${ }^{12}$ Así mismo, encontramos diferentes puntos de vista en todo lo relacionado con la sexualidad, objeto de permanente debate. Sin embargo, hay cuestiones fundamentales respecto a las que compartieron una misma perspectiva: la desigualdad de la mujer en la institución matrimonial y la prostitución como forma extrema de opresión patriarcal. Analizaremos sus ideas al respecto teniendo en cuenta las particularidades de las sucesivas generaciones de mujeres feminis$\operatorname{tas}^{13}$, así como las características de las diversas organizaciones sufragistas. $Y$, aunque no puede ser objeto de este trabajo, hay que señalar que esta misma perspectiva respecto a la prostitución fue compartida sin fisuras por todo el socialismo feminista del diecinueve, por autores como Bebel, Engels, Zetkin y la gran teórica rusa Alejandra Kollontai. Los reformadores sociales viajaban y se reunían a menudo, y ya la feminista socialista francesa Flora Tristán había retratado las brutales dimensiones del espectáculo de la prostitución de niñas y mujeres en la Inglaterra del diecinueve. En su obra Paseos por Londres, en el capítulo titulado "Mujeres públicas", detalla y denuncia el tráfico internacional de mujeres para su prostitución y algunas de las prácticas más habituales de los caballeros ingleses en los burdeles ${ }^{14}$.

Las mujeres nacidas antes de 1850 bajo la moral victoriana, como Millicent Garrett, Frances Power Cobbe, Josephine Butler, Elizabeth Wostenholme, Frances Swiney..., habían centrado sus debates públicos en el derecho a la propiedad, el acceso a la educación, la admisión en la profesión médica, el voto y la custodia de los hijos. Su precaución a la hora de expresar su malestar respecto a cuestiones como el doble rasero sobre la moral sexual, la prostitución y la edad de consentimiento, sólo en círculos más privados, se debió al temor de que estos debates pudiesen perjudicar sus primeras demandas públicas. De ahí, el escándalo y la ruptura del pacto de silencio que provocó la campaña para revocar las Leyes de enfermedades contagiosas, liderada por Josephine Butler a principio de los años 70. La generación que asistió a los acalorados debates, ya públicos, sobre la trata de blancas y la prostitución, y sobre el sometimiento femenino en el matrimonio, puso de manifiesto la hipocresía y las contradicciones de un sistema de dominación en el que la mujer quedaba reducida a la categoría de mercancía. Muchas mujeres, nacidas entre 1850 y 1870 , incorporaron estas denuncias a su discurso en pro del sufragio, a la vez que intentaban llevar estos ideales a la práctica en sus propias vidas, pagando

12. Para un análisis sobre la heterogeneidad del movimiento y cómo muchas sufragistas pertenecían a varias organizaciones simultáneamente, ver $\mathrm{M}^{a}$ Jesús González, "El sufragismo británico: narraciones, memoria e historiografía o el caleidoscopio de la historia", en Ayer, 68 (4), 2007, pp. 273-306.

13. Aunque no se popularizó el término 'feminista' hasta después de 1890, lo utilizaremos para referirnos a las mujeres que lucharon por el sufragio, la abolición de la prostitución y otros aspectos de la igualdad de las mujeres durante este período.

14. Tristan, Flora, Feminismo y socialismo. Antología, Introducción y selección de textos de Ana de Miguel y Rosalía Romero, Madrid, Los Libros de la Catarata, 2002. 
con frecuencia el precio del rechazo y aislamiento social. Mujeres como Emmeline Pethick-Lawrence, dirigente de la Women's Social and Political Union -WSPU-; Olive Schreiner, escritora y feminista radical; Mona Caird, periodista que escandalizaba a la sociedad con sus escritos en contra del matrimonio; Helena Swanwick, activista de la National Union of Women's Suffrage Societies -NUWSS-, creada en 1897, o Sarah Ground, alcaldesa de Bath, que abandonó a su marido, son tan sólo algunos ejemplos.

La campaña sufragista alcanzó su momento álgido en torno a 1910, cuando se intensificó la actividad militante en la calle y el gobierno liberal parecía haber declarado una guerra abierta y violenta al movimiento. El ambiente facilitó que mujeres jóvenes -la tercera generación de sufragistas- vieran sus preocupaciones sobre la sexualidad como algo inseparable de la lucha política por el voto. Reclamaban abiertamente en sus actividades públicas y en sus escritos la deslegitimación de la doble moral sexual, el contrato matrimonial y la prostitución. Además añadieron a su agenda de discusión temas antes impensables como la maternidad, la anticoncepción, la violación, el incesto, la homosexualidad y el derecho de las mujeres al placer sexual. Mujeres como Teresa Billington, militante de la WSPU y posteriormente de la Women's Freedom League, recordaba con angustia la infelicidad y el sometimiento sexual de su madre a su padre, hecho respaldado por las costumbres, la ley y la iglesia; o Cicely Hamilton, que se hizo feminista el día en que comprendió que la moralidad y la 'virtud' en las mujeres se correspondían con un estado físico de virginidad que no siempre dependía de ellas, mientras que en el hombre se refería a cualidades humanas en sentido amplio. ${ }^{15}$

La National Society for Women's Suffrage -NSWS- ${ }^{16}$ había apoyado activamente las campañas contra la regulación de la prostitución de Josephine Butler. De hecho, su presidenta Lydia Becker, y también Elizabeth Wolstenholme, estuvieron muy comprometidas con la causa, a pesar de sus diferencias en torno a la religión o a las 'uniones libres'.

La WSPU se creó bajo el liderazgo de Emmeline y Christabel Pankhurst en 1903, con un planteamiento militante -frente a las constitucionalistas de la NUWSS- y más radical, como organización exclusivamente femenina que rechazaba las alianzas con partidos y colectivos masculinos. Christabel Pankhurst escribió en 1913 The Great Scourge and How to End It, denunciando que los hombres británicos -tres de cada cuatro- estaban contagiando a las mujeres y a sus hijos enfermedades venéreas. Para ella, tras el virulento rechazo de los hombres al voto de las mujeres se hallaba el temor a que las mujeres les impusieran un nuevo código de moralidad. Su planteamiento fue criticado como 'puritano' y basado en datos poco precisos. Sin embargo, la importancia del

15. Para un análisis de la visión de las diferentes generaciones de sufragistas, ver Susan K. Kent, Sex and Suffrage in Britain, 1860-1914, London, Routledge, 1990.

16. La NWSS junto con otras sociedades similares se unirían en 1897 para formar la NUWSS, tras la muerte de Lydia Becker. 
escrito, así como el rechazo que suscitó, residen en que contribuyó a visibilizar y responsabilizar a los hombres como consumidores de mujeres prostituidas que quedaban exonerados tras contagiar a sus familias. Relacionaba la expansión de las enfermedades venéreas con la sujeción de las mujeres relegadas al estatus de objetos sexuales. Dentro de la misma organización hubo mujeres que condenaron la prostitución pero que defendieron ideas avanzadas para su época respecto a las relaciones de pareja y el control de la natalidad. No obstante, el miedo al contagio influyó en las actitudes de muchas mujeres, que recibían con cautela las ideas de libertad sexual fuera de la pareja monogámica.

Durante la primera guerra mundial, resurgió la idea de controlar las enfermedades venéreas a través de una legislación similar a la puesta en marcha en los años 60 y 70 del siglo XIX. Esta medida formaba parte de una ley más amplia, conocida como DORA o Defence of the Realm Act, que reprimió las libertades civiles elementales durante este período. La socialista y feminista Sylvia Pankhurst, junto con su organización, la Workers' Suffrage Federation, aglutinaron el movimiento de protesta contra estas leyes, que volvían a culpar a las mujeres y a justificar a los hombres. Conoció de cerca la explotación de las mujeres en talleres y fábricas y el riesgo de que recurriesen a la prostitución, una 'esclavitud que sólo puede degradarnos cuando la aceptamos'17.

La Women's Freedom League, organización que se había escindido de la WSPU en 1907, responsabilizó a los hombres de la opresión sexual de las mujeres en todas sus formas. En su periódico, The Vote, escribieron acerca de la ineficacia e hipocresía de un Estado que decía proteger a las mujeres, como defendían los anti-sufragistas. Denunciaron la indulgencia de la justicia hacia los hombres en casos de violación y abuso de menores. En sus palabras, "... hablar de la pureza de las mujeres es una hipocresía. En el matrimonio la mujer ha de ser pura para su marido; en los burdeles una víctima pura se vende a precios más elevados; en los tribunales, la castidad es una mercancía de mucho menos valor que la propiedad. Mientras tanto, los hombres parlotean acerca de la pureza..."18.

Aunque no podemos citar a todos los colectivos y publicaciones que influyeron en la difusión de las nuevas ideas feministas acerca de la doble moral sexual, sí queremos destacar el papel de la publicación The Freewoman, dirigida entre 1911 y 1912 por las sufragistas Dora Marsden y Mary Gawthorpe, que habían militado en la WSPU. Esta revista cubría informaciones sobre asuntos que preocupaban en los ambientes sufragistas, aunque sus líderes o bien no las aprobaban o temían que las acusaciones de inmoralidad pudiesen empañar sus campañas. Sus lúcidos análisis sobre la maternidad impuesta, sobre el derecho de las mujeres al placer sexual desde la autonomía y la libre decisión, sobre el control de la natalidad y la tiranía del matrimonio, resultaban muy avanzados

17. Dodd, K., The Sylvia Pankhurst reader, Manchester University Press, 1993, p. 67.

18. Garner, Les, Stepping stones to women's liberty: Feminist ideas in the women's suffrage movement, 1900-1918, Rutherford (NJ), Fairleigh Dickinson University Press, 1984, p. 38. 
para la época. En ningún momento se contemplaba la prostitución como una forma de libertad sexual para las mujeres, sino todo lo contrario, como una manifestación del sometimiento femenino y el mantenimiento de los privilegios masculinos. Estas ideas constituyen un antecedente claro del feminismo radical de los años sesenta y setenta del siglo veinte, años en que se publican obras tan decisivas como Política sexual de Kate Millett y La esclavitud sexual de las mujeres, de Kathleen Barry ${ }^{19}$. Para todas ellas, mujeres liberales y socialistas, religiosas, agnósticas y ateas, la prostitución constituía un modo de degradar y someter a las mujeres a los hombres. Lejos de ser "puritanas", su rebeldía y las libertades que se tomaron en su vida personal y cotidiana comenzaron a poner los cimientos de la futura revolución sexual.

Por eso, como veremos en el siguiente apartado, las feministas rechazaron culpabilizar a las prostitutas de las enfermedades de transmisión sexual y comenzaron a señalar a los 'clientes' y a los proxenetas, incluido el Estado, como los responsables. Iniciaron un movimiento desde el que comenzaron a difundir la idea de que, al igual que se había logrado abolir la esclavitud en muchos lugares del mundo, estaban convencidas de que la prostitución, esa forma extrema de explotación y violencia de género, también podría algún día dejar de existir.

\section{La figura y el movimiento de Josephine Butler}

La aportación de Josephine Butler al feminismo parece haber sido eclipsada, y seguramente no es casual, sino que responde a su determinación de afrontar un tema que la mayoría sigue prefiriendo ignorar, dejar bajo la alfombra. Butler fue una pionera en dos cuestiones fundamentales. Por una parte, se enfrentó al tabú victoriano que silenciaba todo lo relativo a la sexualidad, contribuyendo a visibilizar la perspectiva de las mujeres acerca de asuntos 'poco respetables'. Y además, como líder de un movimiento social, cuestionó la idea de que las mujeres no pudieran actuar como sujeto político independiente. Hasta entonces las mujeres habían participado activamente en el movimiento anti-esclavista, contra las leyes del maíz o en los colectivos recientemente creados a favor del sufragio femenino. Pero a Butler se la conoció en seguida como una de las primeras activistas políticas a nivel nacional.

Nacida en 1828, la séptima de diez hermanos, creció en una familia acomodada de propietarios con fuertes convicciones cristianas basadas en la tolerancia y la libertad de conciencia, y comprometida al mismo tiempo con las ideas liberales. Su padre, John Grey, fue un acérrimo defensor de la causa abolicionista cuando la oposición a la esclavitud era aún bastante minoritaria. En la familia existía una tradición de mujeres cultas e independientes y un

19. Millet, Kate, Política sexual, Madrid, Cátedra, 2010 y Barry Kathleen, La esclavitud sexual de las mujeres, Barcelona, Ediciones laSal, 1988. 
ambiente marcado por valores humanistas y solidarios en el que se reconocía la igualdad de la mujer, sobre todo su derecho a la educación y a la participación política. Los Grey habían inculcado a Josephine 'un odio encendido hacia cualquier forma de injusticia'20.

Apoyada incondicionalmente por su marido, George Butler, y con la experiencia política adquirida en las campañas contra la esclavitud de los negros en los años cuarenta, Josephine Butler se enfrentó al reto de denunciar las Leyes de enfermedades contagiosas, las Contagious Disease Acts, también conocidas como las CD Acts. Estas leyes habían sido sucesivamente aprobadas por el Parlamento en 1864, 1866 y 1869, y pretendían regular estatalmente la prostitución en las ciudades y puertos militares, con el objeto de controlar las enfermedades venéreas que se extendían como una epidemia. Estas leyes otorgaban a los hombres, magistrados, policías y médicos, el control sobre el cuerpo de las mujeres, en aras de una supuesta mejora de la salud pública. Se culpaba a las mujeres en situación de prostitución de provocar el deterioro de la salud y del bienestar de toda la población, hombres, mujeres y bebes recién nacidos. Y podían ser detenidas y acusadas de ejercer la prostitución, sólo con que un policía declarara que así lo parecía. Las mujeres eran consideradas culpables hasta que no demostrasen su inocencia, es decir, se les negaban los derechos elementales a los que podía acogerse cualquier presunto criminal. Además se les presionaba para firmar el consentimiento de someterse a exámenes médicos agresivos y degradantes que decidirían su internamiento en determinados hospitales. Si no aceptaban, eran condenadas a penas de cárcel. Carecían de los derechos de Habeas Corpus, de ser juzgadas ante un jurado y del derecho de apelación.

El caso es que había mujeres que incluso preferían ir a prisión antes que pasar por el suplicio del examen médico, con un instrumental y unas condiciones higiénicas que propiciaban los desgarros y las infecciones. Butler recogió espeluznantes testimonios de mujeres acerca del maltrato recibido en estas inspecciones, que vivían como auténticas violaciones. No se tenía en cuenta que estuvieran ni enfermas ni embarazadas ${ }^{21}$, que acabaran de ser madres o estuvieran menstruando. A ningún hombre, en cambio, se le exigía demostrar su buen estado de salud genital para no contagiar a la población sana, cuando la revisión es mucho más sencilla ${ }^{22}$. Este modelo regulacionista se inspiraba en el ya ensayado en varios países europeos.

20. Para una descripción de las primeras influencias en la vida de J. Butler, ver el capítulo primero de la obra de Jane Jordan, Josephine Butler, London, John Murray, 2001.

21. En la ley de 1869 se incluyeron cláusulas que limitaban las inspecciones en caso de embarazo.

22. Actualmente las asociaciones de proxenetas utilizan el buen estado de salud sexual de las mujeres como reclamo para atraer a 'clientes' a su negocio. También ciertas posiciones reglamentaristas argumentan acerca de una mejor protección sanitaria para las mujeres prostituidas, sin mencionar el hecho de que para los 'clientes' no es obligatorio demostrar su buen estado de salud genital. 
La iniciativa para aprobar las leyes había partido de sectores políticos que, preocupados por la desastrosa actuación de los militares británicos en la guerra de Crimea, pretendían acallar las críticas a la ineficacia de sus oficiales. El chivo expiatorio resultó ser el mal estado físico de la tropa debido a las enfermedades venéreas transmitidas por las mujeres prostituidas. Se produjo así una alianza entre el estamento militar y ciertos sectores de la salud pública ligados a la revista médica The Lancet ${ }^{23}$, para asegurar el suministro de mujeres libres de este tipo de enfermedades para los soldados ${ }^{24}$. Mujeres ligadas a temas de salud como Harriet Martineau, Florence Nightingale y buen número de médicos criticaron en la prensa estos planteamientos con escaso éxito. La ley que se aprobó en 1869 permitía un período de detención de las mujeres de hasta nueve meses. Fue precisamente en este año cuando Butler, a instancias de la educadora y sufragista Elizabeth Wolstenholme ${ }^{25}$, se comprometió definitivamente con la revocación de estas leyes y aceptó presidir la Ladies National Association for the Repeal of the Contagious Diseases Acts (LNA). El movimiento contra las leyes no tenía un carácter local. Butler también se reunía con mujeres francesas, alemanas, italianas, rusas y suizas que luchaban en sus países contra esta nueva discriminación legal hacia las mujeres. Se formó la International Women's Association, con el objeto de coordinar esfuerzos para la abolición del sistema de regulación estatal de la prostitución.

A comienzos de 1870 Butler publicó en el Daily News un manifiesto contra estas leyes firmado por ciento cuarenta mujeres, entre ellas Mary Carpenter, Lydia Becker, Harriet Martineau y Florence Nightingale, un verdadero documento fundacional del movimiento feminista británico. Las sociedades y comités por la revocación de las leyes se multiplicaron en pocos meses por todo el país. A pesar de que el debate se desarrolló de forma transversal a los diferentes ámbitos profesionales y partidos políticos, fueron un grupo de parlamentarios liberales, entre los que se hallaban Fowler, Stansfeld, Bright o Johnstone, quienes además del filósofo John Stuart Mill, dieron la batalla dentro de la Casa de los Comunes.

Butler poseía un talento especial para hablar en público y para convencer. Encontró una audiencia predispuesta a sus posiciones entre los sindicatos y los trabajadores, ya concienciados acerca del peligro que suponía para las mujeres de sus familias, tanto el mercado prostitucional, que se nutría de las más necesitadas, como el acoso policial. Las mujeres y niñas de la clase trabajadora eran especialmente vulnerables. Pasaban mucho tiempo en la calle para ganarse la

23. En 1867 The Lancet abogó por la extensión de la ley a la totalidad del país.

24. Fisher, Trevor, "Josephine Butler. Feminism's Neglected Pioneer", en History Today, vol. 46 (6), pp. 32-38, 1996.

25. Elizabeth Wolstenholme era conocida en los círculos sufragistas por su defensa de la laicidad y de las 'uniones libres'. De hecho sufrió un fuerte rechazo por vivir con su compañero, Ben Elmy, con quien se casó, ya embarazada de varios meses, debido a la presión social. En la causa contra la regulación de la prostitución confluyeron mujeres de fuertes convicciones religiosas con otras librepensadoras y ateas. 
vida en condiciones de explotación y la mayoría eran analfabetas, por lo que no estaban preparadas para defender sus derechos en caso de ser detenidas. Esta situación de servidumbre y peligro a la que estaban expuestas las obreras en el espacio público, ser "mujeres públicas", constituía algo normal y natural para los hombres de las clases medias y altas, mientras predicaban el enclaustramiento en la esfera privada para sus esposas e hijas.

En sus campañas Butler atacaba tanto la dominación de sexo como la de clase. No compartimos la visión difundida por algunas autoras de que su actuación representara una suerte de paternalismo moralista, característico de las mujeres de clase media respecto a las más pobres ${ }^{26}$. A Butler le indignaba la injusticia en cualquiera de sus formas, lo que también le llevó a abrazar causas como la abolición de la esclavitud o la independencia de Irlanda. Denunció la miseria y el hambre que acuciaban a las mujeres en prostitución e instaba a quienes la escuchaban a comprender el problema desde la empatía, negándose a la diferenciación, comúnmente aceptada, entre mujeres castas y no castas; planteamiento subversivo para la época: " ¿No son acaso seres humanos como nosotros con corazón y conciencia? ...Bajo estas leyes ya no se las trata como a mujeres sino como a trozos de carne numerada, inspeccionada y etiquetada para su distribución en el mercado público por parte del Gobierno"27.

Se oponía a la criminalización de las mujeres prostituidas y su actitud hacia ellas era de empatía y de solidaridad. Pensaba que, mediante una mayor sensibilización, apoyo social y un cambio en la legislación, la vida de estas mujeres podría mejorar.

Reivindicó para estas mujeres oprimidas y amenazadas, sus 'hermanas', el derecho a la auto-defensa y a la resistencia. Como dijo en 1875: "Ahora hablan las esclavas. Han encontrado entre ellas una igual, la voz que las representa." 28 Su discurso no era puramente teórico o político sino que partía de un acercamiento previo a las vidas de las mujeres y niñas que ejercían la prostitución. Antes de aprobarse las leyes había estado en contacto con esta realidad a través de su experiencia en el trabajo social. Estaba informada también de los conflictos, con policías, médicos y jueces, de aquellas mujeres a las que se les había aplicado las leyes de enfermedades contagiosas. Conocía los burdeles y hablaba con las prostitutas pero era también realista, pues comprendía la dificultad que suponía sobrevivir, ya fuera con salarios insuficientes a cambio de jornadas interminables de trabajo en condiciones insalubres, o en la indigencia.

Butler y sus compañeras denunciaban cómo estas leyes nunca explicitaban el crimen cometido, y cómo se habían aprobado sin el conocimiento ni el con-

26. Walkowitz, Judith, "The Politics of Prostitution", en Signs, vol. 6 (1), 1980, pp. 123-135.

27. Ver el capítulo séptimo de la obra de Jane Jordan, Josephine Butler, London, John Murray, 2001.

28. Citado en Anne Summers, "The Constitution Violated: the Female Body and the Female Subject in the Campaigns of Josephine Butler", en History Workshop Journal, vol. 48 (1), 1999, pp. 1-15. 
sentimiento de las personas afectadas. Y lo más injusto era que castigaba a un solo sexo, violentando el cuerpo, la libertad y los sentimientos de las mujeres. Al igual que en otros países, se justificaba la prostitución como algo necesario e irremediable, sin cuestionarla ni ética ni políticamente. Criticaban a un Gobierno que en ningún momento se había preocupado de combatir las causas sociales y económicas de la prostitución. Butler aseguró que no cesarían hasta conseguir unas leyes basadas en un código igualitario para hombres y mujeres, acabando con el doble rasero respecto a la moral sexual dominante. Además, no aceptaban que la idea de moralidad estuviese definida por los hombres en base a sus intereses y privilegios.

En cuanto al activismo, Butler apostó, al igual que lo haría el movimiento sufragista en su fase militante ${ }^{29}$, por visibilizar la causa entre todo tipo de audiencias y por acosar a los candidatos políticos antes de las elecciones. Amenazaban con hacer campaña en su contra si no se comprometían a derogar las Leyes de enfermedades contagiosas. Fueron objeto de críticas, calificadas de 'peor que prostitutas', y también agredidas verbal y físicamente. Combinaron las tareas de apoyo a las mujeres afectadas -generando fondos para el cuidado de los hijos e hijas de las internadas y para hacer frente a los gastos derivados de su defensa legal- con la divulgación de la causa en ámbitos profesionales, en la prensa y en la calle, manifestándose además en las puertas de los burdeles para denunciar la situación de las mujeres y para señalar a los hombres como los máximos responsables.

Butler denunció la trata de blancas para la prostitución, que incluía a niñas entre 10 y 14 años. La campaña logró que se elevase la edad de consentimiento de los 14 a los 16 años, así como endurecer la ley respecto a los propietarios de burdeles. Estas medidas estuvieron influidas por la campaña sensacionalista iniciada por el periodista W.T. Stead, de la Pall Mall Gazette, que logró conmover a parte de la sociedad demostrando la facilidad con la que se podía 'comprar' una niña. Este hecho contribuyó a acelerar la revocación de las leyes. Sin embargo, también conformó en torno a la figura del periodista una nueva cruzada de moral victoriana que cristalizó en la formación de la National Vigilance Association. Los valores de este colectivo nada tenían que ver con el humanismo y la solidaridad feminista de Josephine Butler, quien finalmente optó por distanciarse del mismo, ya que no compartía sus actitudes represivas ni su consideración de las mujeres prostituidas como mujeres inmorales ni enemigas a batir.

Butler comprendió en todo momento que las razones morales y solidarias feministas no tendrían suficiente peso para mover a los políticos a su favor. Por ello recurrió también a los argumentos políticos y constitucionales al uso.

29. Las sufragistas militantes del periodo eduardiano vieron en Butler un modelo, en cuanto a la táctica política de tener presencia física en todos los espacios públicos, incluida la calle. Feministas de ese período (1905-1914) la reconocieron como 'la gran madre fundadora del feminismo moderno'. 
En su obra, The Constitution Violated, advirtió que el nivel general de libertad política de un país dependía de que se respetasen los derechos de todas las personas. Una legislación justa sólo podría darse cuando las mujeres estuvieran adecuadamente representadas a través del sufragio. Para ello animaba a una revuelta permanente que 'volviese el mundo del revés si era necesario', hasta conseguir eliminar todo rastro de injusticia de unas leyes hechas por y para los hombres. ${ }^{30}$ Finalmente, y tras una movilización y activismo de mujeres sin precedentes denunciando la impunidad de la explotación sexual, se consiguió cambiar la voluntad del poder político y que finalmente el gobierno liberal revocase las leyes en 1886.

\section{La argumentación de John Stuart Mill ante la Comisión Parlamentaria: con- tra la penalización de las prostitutas y la impunidad de los puteros}

Las primeras leyes sobre las enfermedades contagiosas habían pasado sin apenas oposición por el parlamento británico. Un parlamento del que las mujeres estaban absolutamente excluidas, incluso como público, pero como ya hemos expuesto no había sucedido lo mismo en la sociedad. En la sociedad civil se fue conformando un movimiento liderado y militado por mujeres que se ha llegado a describir como "la primera revuelta femenina de estatura"

Gracias a esta fuerte movilización social el gobierno anunció que convocaría una comisión de notables para fundamentar mejor su posición. La comisión constaba de veintitrés personas, todas varones, entre los que se incluían diez parlamentarios, algunos clérigos y algún científico célebre como T.H. Huxley. Los opositores mantenían que la comisión estaba hecha a medida para legitimar la aprobación de las Leyes pero parece que no era así, que también los había contrarios y neutrales ${ }^{32}$. En 1870 John Stuart Mill fue convocado, junto con otros notables del reino, para expresar su opinión sobre las Leyes encaminadas a prevenir lo que se consideraba un problema de salud pública, el contagio por las enfermedades de transmisión sexual, la sífilis y otras. A lo largo de la década de los sesenta se habían aprobado tres leyes en el Parlamento. En todas ellas el peso de la ley recaía exclusivamente sobre las mujeres. La primera (1864), obligaba a revisarse a cualquier mujer prostituta de la que se alegara que estaba infectada, con médicos oficialmente designados para ello.

30. Butler, Josephine, The Constitution Violated. An Essay, Cheshire, Portrayer Publishers, 2003.

31. Cfr. Pearson, Michael, The Age of Consent: Victorian prostitution and Its enemies, Newton Abbot, David and Charles, 1972, p. 173 y González Hernández, Mª Jesús, "Las sufragistas británicas y la conquista del espacio público: integración, recreación y subversión" en prensa en Arenal, p. 7. Agradecemos a Laura Torres que nos haya proporcionado este magnífico texto aún inédito.

32. Seguimos en este aspecto el texto de Jeremy Waldrom "Mill on Liberty on the Contagious Diseases Acts" en Urbinati, Nadia y Alex Zakaras eds., J. S. Mill's Political Thought. A Biccentennial Reassessment, Cambridge, Cambridge University Press, 2007. 
Si estaba infectada se le podía recluir a la fuerza durante tres meses en un hospital especial. La segunda (1866) creaba una especie de fuerza médica policial para patrullar los puertos y ciudades "peligrosas" para obligar a las mujeres con pinta de prostitutas a examinarse los genitales. En 1869 una tercera ley obligaba a las prostitutas a registrarse oficialmente y llevar consigo un carné que certificara que su carne estaba en buen estado para los varones. Bueno, realmente la ley no lo expresaba así, pero no creemos traicionar su espíritu por decirlo con estas sencillas palabras.

La postura de Mill a lo largo de todo el interrogatorio fue la de una oposición inquebrantable y absoluta a la aprobación de la ley33. La primera razón esgrimida: supone una intromisión ilegítima en la libertad de las mujeres. Por un lado, cualquier mujer puede, según el particular criterio de cada miembro del cuerpo policial, tener rasgos externos de prostituta. Por otro lado, y de acuerdo con el principio de libertad, ningún adulto no enajenado o loco puede ser coaccionado a someterse a un reconocimiento médico. Sin embargo, en la búsqueda de una respuesta más satisfactoria al interés real de la comisión, que en el interrogatorio a John Stuart Mill sí apunta a que era la aprobación de la Ley, un miembro del tribunal le plantea el caso como uno de daño a los intereses-derechos de los demás. Le piden que reflexione y pase a tener en cuenta que son muchos los inocentes, mujeres y niños, finalmente contagiados por la enfermedad. Ante esta dolorosa observación Mill responde que, entonces es a los varones responsables del contagio a inocentes, presumiblemente sus esposas y sus hijos, a quienes se debe someter a revisión médica obligatoria y sobre quienes, en caso real de contagio debe caer todo el peso de la ley. En concreto se refiere a que la mujer contagiada tenga derecho a solicitar y que se le conceda el divorcio. Hoy nos puede parecer incomprensible, pero lo que en aquellos momentos escandalizaba era escuchar a John Stuart Mill defender el derecho al divorcio de las mujeres, no el que sus maridos fueran con prostitutas. Y, por supuesto, se daba por sentado que las culpables del contagio eran las pérfidas e insensibles mujeres prostituidas.

Según avanza el interrogatorio por parte de la comisión, Mill dará otra explicación de su tajante negativa a la aplicación de la Ley: el estado no puede legitimar una acción proxeneta o convertirse en un estado proxeneta avalando y legitimando con su poder material, legal y simbólico un mercado para la prostitución de mujeres. El Estado no puede, de acuerdo con el principio de libertad, penar la prostitución pero menos aún puede fomentarla, donde se entiende que fomentarla sería poner las condiciones antes señaladas para pre-

33. La declaración de John Stuart Mill está recogida en sus obras completas. En estos momentos está en prensa la traducción realizada por Paloma Albadalejo en una edición crítica de este y otros textos feministas inéditos a cargo de Ana de Miguel. Cfr. John Stuart Mill, De la teoría a la práctica: tres documentos históricos en la lucha por los derechos de las mujeres, Almud, ediciones de Castilla la Mancha, en prensa. 
venir los contagios ${ }^{34}$. No puede enviar el siguiente mensaje: ¡tranquilos, ya nos encargamos de supervisar la mercancía! Por supuesto, Mill afirma que el Estado debe hacerse cargo de las víctimas de la sífilis, pero nunca introducir entre sus atribuciones el ofrecer mujeres prostituidas en buen estado de salud física (genital). Mill, como las sufragistas, siempre objetó la doble moral sexual y esa rancia indulgencia con la "debilidad masculina", indulgencia que recorría todo el arco ideológico; desde las religiones a las filosofías laicas y a menudo supuestamente transgresoras y que al final en el tema de la prostitución, siempre coinciden con las posturas que, en otros aspectos, califican de conservadoras y puritanas. Todos se ponían de acuerdo en conservar la prostitución, ya fuera por considerarla "un mal menor" o una "transgresión antiburguesa" ${ }^{35}$.

El Estado es para el filósofo inglés un poderoso agente de influencia social, y su poder normativo y ejemplar, indudable. Si bien no debe imponer más elecciones de las necesarias, mucho menos debe facilitar comportamientos que benefician a una parte y perjudican a la mayoría. Para Mill es indispensable salvaguardar férreamente el área de autodeterminación de las personas ya que en su filosofía vivir es elegir. Pero al mismo tiempo el filósofo que ha definido la autonomía como la capacidad real de elegir entre distintas opciones, no puede convertir esta férrea defensa del antipaternalismo en hacer pasar por elecciones libres y fruto de la individualidad las que de ninguna forma lo han sido. $Y$ es que en sociedades marcadas por la desigualdad sexual y por la pobreza hay que situarse en las posiciones neoliberales más extremas para sostener que las prostitutas eligen serlo. En este sentido Mill aparece como uno de los autores en que la gran aportación del liberalismo, la defensa de la autodeterminación y el despliegue de la individualidad, no se convierte en una coartada para que la sociedad y el estado puedan desentenderse de conductas que, bajo la apariencia del consentimiento, encubren en la práctica situaciones de opresión y servidumbre, es decir, todas aquellas situaciones en que el ejercicio de la individualidad se ha limitado a "escoger" la única opción posible.

El argumento del filósofo moral es inquebrantable, y lo es a pesar del acoso que sufre por parte de algún miembro de la comisión. El caso es que el gobierno estaba encontrando serios obstáculos cuando durante décadas sus leyes se habían aprobado sin oposición alguna. ¿Cómo se había defendido la necesidad de que el estado concediera un estatuto tan especial a esta enfermedad contagiosa frente a otras igualmente dañinas? ¿Cómo se había argumentado la legitimidad de esta atención tan especial frente a otros problemas de salud al menos tan acuciantes como el que comentamos? Las leyes se encuadraban de forma explícita en la sentida preocupación por los cerca de 270.000

34. Cfr. John Stuart Mill, Sobre la libertad, Madrid, Alianza Editorial, 1976.

35. Cfr. Los magníficos ensayos de Alicia Puleo sobre la vuelta de esta rancia moral de la transgresión y recogidos en su libro Ecofeminismo para otro mundo posible, Madrid, Cátedra, 2011; especialmente los capítulos "Sexualidad, fundamentalismos y discursos transgresivos y liberación del Eros en las sociedad del riesgo". 
miembros de las fuerzas armadas británicas. Se supone que un tercio de los soldados contraía enfermedades venéreas y de hecho en la comisión aluden continuamente a los soldados. Sin embargo hay que enfatizar que en el texto se trasluce claramente cómo la preocupación se extiende a todos los clientes y se centra especialmente en los hombres casados, en los padres de familia. Efectivamente, según avanza el debate observamos la reiteración de que uno de los problemas era el contagio a mujeres y niños "inocentes", es decir a las esposas y a las esposas embarazadas, lo que propiciaba en algunos casos la muerte de ambos. Y, si tal y como se afirma la armada no permitía a la mayor parte de los soldados contraer matrimonio ${ }^{36}$ tenemos que concluir que uno de los perfiles habituales era el de civiles, hombres casados, digamos "decentes y honorables". Es importante señalar esto porque, tanto hablar de los soldados, parece que la prostitución se quiere conceptualizar -y con ello comprender y disculpar- como una cosa de chicos jóvenes, rudos pero valientes y valerosos defensores de la patria, y no era este, ni mucho menos, el único perfil de los prostituidores.

Mill insiste una y otra vez; si realmente se quiere hacer algo positivo en este tema hay que dirigirse a los auténticos responsables del contagio a inocentes: los varones que van con prostitutas, los clientes, los puteros. Los puteros que además luego se acuestan también con sus esposas, esposas que como hemos visto arriba no tienen ni siquiera derecho al voto, y les contagian la enfermedad, y como insisten los miembros de la comisión, cuando ellas están embarazadas se la transmiten también a los que han de nacer. Mill continúa inquebrantable: ¿con qué cara atreverse a culpar de este contagio a las prostitutas? Los maridos son los únicos culpables de toda la cadena de acciones, los únicos que saben lo que están haciendo y a quienes se lo hacen. "Creo que si la prevención debe aplicarse, debería aplicarse al hombre, que es el único que puede cometer la falta de manera directa. Cuando una mujer contagia a alguien, el hombre forzosamente consiente en correr el riesgo: solamente un hombre que se ha contagiado puede comunicar la infección a una persona inocente, y por lo tanto si hay algún argumento para la prevención debe ser favorable a medidas preventivas aplicadas a los hombres que contagian a las mujeres" ${ }^{\prime 37}$.

El filósofo radical John Stuart Mill plantea también la necesidad de que haya sanciones penales y sociales graves para los hombres que contagian a sus esposas, la gravedad de las penas y el rechazo social a los delincuentes de este tipo actuaría como una palanca de cambio social y de mentalidad. El conocimiento de estas penas, observa Mill, pondría coto al contagio y "haría que este delito fuese considerado como en realidad es, uno de los más graves

36. Smith, F.B., "Ethics and Disease in the later Ninenteenth Century; The Contagious Diseases Acts", en Historical Studies, no 15, 1971, pp. 118-39.

37. Mill, John Stuart, De la teoría a la práctica: tres documentos históricos en la lucha por los derechos de las mujeres, Almud, Ediciones de Castilla La Mancha, en prensa. 
que un hombre puede cometer". Los miembros de la comisión no debían dar crédito a lo que estaban escuchando. Seguramente era la primera vez en la historia que un pensador cuestionaba el derecho de los varones a acceder al cuerpo de las mujeres por un precio variable. La ley patriarcal que sostiene como un derecho básico el imperativo de que los varones puedan satisfacer su apetito sexual. Y a que la sociedad le proporcione, de una u otra manera, una cantidad suficiente de mujeres prostituidas ${ }^{38}$.

Las leyes serían finalmente rechazadas en 1886. Para conseguir este objetivo muchas mujeres y hombres, muchas personas lucharon denodadamente, a menudo ante la incomprensión de la mayor parte de la sociedad; sociedad que asumía "la necesidad" de disponer de prostitutas como algo incuestionable. Y que por tanto la sociedad de una u otra forma tiene que garantizar el cuerpo de esas mujeres, como cualquier otra mercancía, en el mejor estado posible. Frente a este estado de cosas, en que se percibe la realidad social como algo a lo que los seres humanos sólo pueden tratar de adaptarse lo mejor posible -la idea es: dado que algo existe, legislémoslo lo mejor posible- el feminismo argumentó de la forma que históricamente le ha sido propia. El feminismo siempre ha transformado lo existente, la realidad, en función de sus principios y bajo una máxima de reciprocidad. Si la norma de acción del feminismo hubiera sido plegarse de forma pragmática a la realidad, las mujeres nunca hubieran llegado a transformar un estado de cosas tan universal y longevo como era y es el orden jerárquico del patriarcado ${ }^{39}$.

\section{Conclusiones}

El feminismo, como teoría y como movimiento social, inició y desarrolló a lo largo de todo el siglo diecinueve un proceso de deslegitimación de la prostitución y de activismo en contra de la legalización de un mercado de cuerpos femeninos amparado por el estado. Este proceso estuvo estrechamente ligado al desarrollo y consolidación del movimiento feminista en Inglaterra. Como es sabido, el sufragismo fue mucho más que la lucha por el voto. La demanda de ciudadanía para las mujeres se intuía y teorizaba -de ahí la férrea oposición que tan a menudo suscitaba- como un factor que alteraría todo el orden social, las valoraciones morales incluidas. Las sufragistas $-y$ también las socialistas y comunistas- reflexionaron sobre la sexualidad y todas coincidieron en condenar con dureza la doble moral sexual. Entre su forma de entender la igualdad se encuentra un duro y crítico análisis de la prostitución de mujeres.

38. Véase "What is Wrong with Prostitution" el magnífico capítulo de la obra de Carole Pateman El Contrato Sexual. Está traducida al castellano por Maria Luisa Femenías en la editorial Anthropos.

39. Señala Amelia Valcárcel que el feminismo es la gran palanca de innovación moral y normativa en el mundo actual. Cfr. Feminismo en un mundo global, Madrid, Cátedra, 2008. 
La ideología patriarcal al uso consideraba la prostitución o un mal menor o un bien que la sociedad democrática debía proporcionar a los ciudadanos varones. $Y$ es que la visión tradicional, es decir, patriarcal, de este tipo de intercambio ha oscilado y oscila entre su consideración como algo normal y necesario en el sentido de natural, anclado en la naturaleza diferente de los sexos y en sus relaciones personales, y su consideración como una práctica transgresora y antiburguesa, cuando en realidad los burgueses han sido tan asiduos de los prostíbulos como el resto de las clases sociales. Los padres Ilevaban tradicionalmente a sus hijos a los burdeles para iniciarles en sus derechos en la sociedad patriarcal, ¿dónde está la transgresión?

Las feministas, como es habitual en los movimientos sociales, diferían en las cuestiones teóricas y políticas y, sin embargo, no lo hicieron en su análisis de la prostitución como una institución clave del poder de los hombres sobre las mujeres: reflejo y reproductor del mismo. Dentro del feminismo había grandes diferencias entre las más pragmáticas y radicales, entre las comunistas, socialistas y liberales, pero todas estuvieron de acuerdo en esto: la prostitución representa una forma extrema de opresión de los hombres sobre las mujeres, de desposesión de su humanidad y de reducción de sus personas a carne comerciable ${ }^{40}$.

Josephine Butler fue convirtiendo la lucha contra aspectos específicos de la prostitución en lo que llegaría a denominarse la causa abolicionista. En un principio centró su estrategia y objetivos políticos en medidas concretas, como la de subir la edad del consentimiento de las prostituidas de los 14 a los 16 años en 1885, pero ha pasado a la historia del movimiento feminista como la fundadora de la posición abolicionista, posición que defiende que la prostitución es producto de la sociedad patriarcal y que puede llegar a ser abolida como en su día lo fue la esclavitud de los negros.

El movimiento de oposición a Las Leyes de enfermedades contagiosas actuó con todas las señas de un movimiento social: tratando de transformar las mentalidades, de conseguir que la ciudadanía pasase a ver con ojos nuevos y críticos "el oficio más viejo del mundo" y desarrollando un activismo militante similar al del sufragismo en sus planteamientos teóricos y su intensidad militante. Las feministas actuaban como podían, escribiendo artículos, repartiendo panfletos, impartiendo mítines y conferencias. Fueron realmente decididas y valientes en una sociedad que, como casi todas -incluso las actuales- no se atrevía a hacer explícita la doble vida de numerosos hombres y, mucho menos, a sustraerles como colectivo su democratizado derecho de pernada, el mercado internacional de prostitución de mujeres. Frente a lo que se ha escrito nunca

40. Asímismo, una crítica radical de estas instituciones definió el feminismo de la segunda ola, el Ilamado feminismo radical. Sólo a partir de la década de los ochenta, a finales del siglo veinte, nos encontramos con posiciones que se autodefinen como feministas y que consideran la prostitución como cualquier otro trabajo y no como un instrumento de dominación patriarcal profundamente lesivo para la vida de las mujeres. 
condenaron ni persiguieron a las prostitutas. Al contrario, lucharon por desplazar la responsabilidad de las enfermedades y la miseria moral que rodea a la prostitución hacia los proxenetas, los puteros y, en última instancia, al estado.

Por último, y al finalizar este artículo, después de una larga investigación que nos ha llevado más lejos de lo que inicialmente pensábamos, no podemos sino dejar una pregunta en el aire, pregunta destinada a nuestra comunidad investigadora y a nuestra ciudadanía democrática y comprometida con una sociedad más igualitaria: ¿cómo es posible que un movimiento de estas dimensiones, de estas características, haya sido y continúe siendo tan desconocido, tan silenciado? 